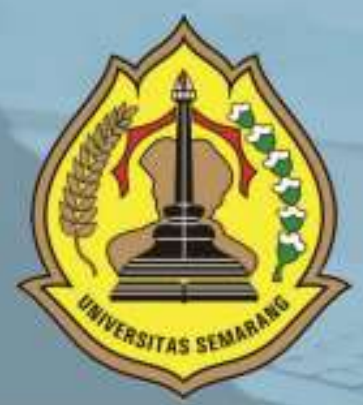

PENGARUH WORK FAMILY CONFLICT, STRES KERJA DAN KEPEMIMPINAN TERHADAP TURNOVER INTENTION KARYAWAN (STUDI PADA SELURUH KARYAWAN BAGIAN PLANNING PRODUCTION AND INVENTORY CONTROL PT. PARKLAND WORLD INDONESIA JEPARA

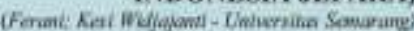

STUDI SOFT SKILL LULUSAN PENDIDIKAN KEJURUAN DI TEMPAT KERJA

Whort-Chiversikio Semorang

ANALISIS IINGKUNGAN INTERNAL DAN EKSTERNAL, PADA UKM PREMIUM PLUS LAUNDRY CABANG MULAWARMAN SEMARANG

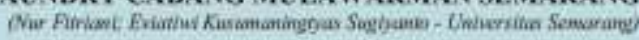

FAKTOR-FAKTOR YANG MEMPENGARUHI PERTIMBANGAN TINGKAT MATERIALITAS AUDIT

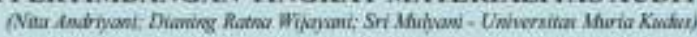

MANAJEMEN LABA DAN FAKTOR-FAKTOR YANG MEMPENGARUHINYA (STUDI EMPIRIS PADA PERUSAHAN MANUFAKTUR DI BEI)

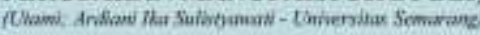

PENDAPATAN ASLI DAERAH, DANA PERIMBANGAN, DAN SISA LEBIH PEMBIAYAAN ANGGARAN TERHADAP PENGALOKASIAN BELANJA MODAL: STUDI PADA KABUPATEN/KOTA DI PROVINSI JAWA TENGAH

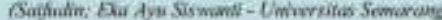

PERSEPSI PENGGUNA JASA TRANS JATENG TERHADAP KUALITAS PELAYANAN ANGKUTAN AGLOMERASI PERKOTAAN TRANS

JATENG

(Studi Kasus Trans Jateng Koridor I Semarang (Tawang) - Bawen)

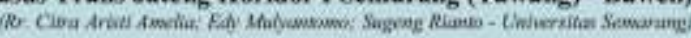

WORTHLESSNESS IS A POWER: MENGAPA ORANG BERSEDIA MENARUH UANG DI APLIKASI GO-PAY

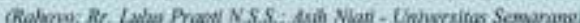

ANALISIS PENGARUH KUALITAS PRODUK, PERSEPSI HARGA, DAN PROMOSI TERHADAP KEPUTUSAN PEMBEIIAN WELLBLUE AL KALINE WATER PITCHER

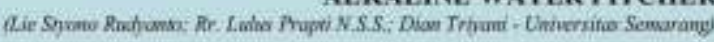

STRATEGI PEMASARAN UNTUK MENINGKATKAN VOLUME PENJUALAN (STUDI KASUS PADA SHOFA CATERING)

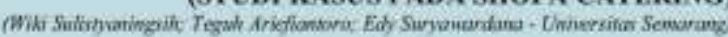

PENGARUH CITRA MEREK, PERSEPSI HARGA, DAN KUALITAS PRODUK TERHADAP KEPUTUSAN PEMBELIAN SEPATU OLAH RAGA MEREK ADIDAS

(Studi di Kota Semarang)

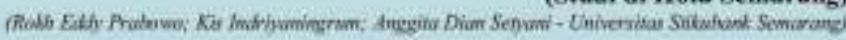

PENGARUH KEMUDAHAN TERHADAP KEPUTUSAN MENGGUNAKAN E-BANKING PADA BNI 46 KC KARANGAYU SEMARANG DENGAN MINAT NASABAH DAN KEPERCAYAAN SEBAGAI VARIABEL. MEDIASI

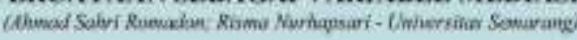

PENELITLAN KEBERLANGSUNGAN USAHA ARDANI INDONESIA SEBAGAI UMKM BERBASIS INDUSTRI KREATIF

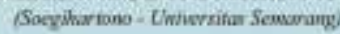

STRATEGI PELAYANAN BUS RAPID TRANSIT (BRT) TRANS SEMARANG

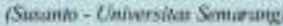

ANALISIS PENGARUH KEPEMIMPINAN, STRES KERJA, DAN LINGKUNGAN KERJA TERHADAP KINERJA KARYAWAN BAGIAN PRODUKSI SEWING PT. SAMWON BUSANA INDONESIA SEMARANG

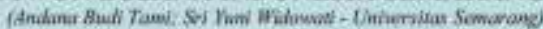




\section{DESKRIPSI}

Majalah IImiah Solusi Mengkaji

Masalah-Masalah Sosial,

Ekonomi dan Bisnis

\section{KETERANGAN TERBIT}

Terbit Pertama Kali Juli 2002

dan SelanjutnyaTerbit Tiga Bulan

Sekali (Januari, April, Juli dan

Oktober)

\section{PENERBIT}

Fakultas Ekonomi USM

\section{ALAMAT PENERBIT}

JL. Soekarno Hatta Semarang

Telp. 024-6702757 Fax. 024-6702272

\section{PENGELOLA}

Editor in Chief : Yohanes Suhardjo, SE, M.Si., Ak, CA Vice Editor Chief : Sugeng Rianto, SE, MM

Managing Editor: Edy Suryawardana, SE, MM

Secretary of Managing Editor : Asih Niati, SE, MM

Administration \& Circulation :

Citra Rizkiana, SE, MM

Layout \& Typesetting : M Burhan Hanif S.Kom, M.Kom

Board of Editors:

1. Prof. Dr. Ir. Kesi Widjajanti, SE, MM (USM)

2. Prof. Drs. Mohammad Nasir, Msi, Ph.D, AK. (USM)

3. Prof. Supramono SE, MBA, DBA (UKSW)

4. Prof. Drs. H. Imam Ghozali, M.Com, Akt, PhD (UNDIP)

5. Prof. Dr. Agus Suroso, MS (UNSOED)

6. Prof. Dr. Widodo, SE, M.Si (UNISSULA)

7. Prof. Dr. Dra. Sulastri, ME, M.Kom (UNSRI)

8. Dr. Ardiani Ika S, SE, MM, Ak, CA, CPA (USM)

\section{KATA PENGANTAR}

Sungguh merupakan kebahagiaan tersendiri bagi kami, takala kami dapat hadir rutin setiap tiga bulan sekali untuk saling bertukar pikiran mengenai hal-hal baru dibidang sosial, ekonomi dan bisnis.

Pada kesempatan ini penerbit menyampaikan terima kasih kepada semua pihak yang telah mengirimkan artikel-artikelnya. Penerbit akan membuka kesempatan seluas-luasnya bagi seluruh kalangan akademisi maupun praktisi baik dari dalam maupun luar Universitas Semarang untuk mempublikasikan karya ilmiahnya.

Penerbitan majalah ilmiah "SOLUSI" kali ini menghadirkan 15 (Lima Belas) artikel yang kami anggap layak untuk diterbitkan, dengan harapan dapat menjadi tambahan referensi bagi para pembaca dan menjadi sumbangan pengembangan persemaian khasanah pengetahuan dibidang sosial, ekonomi dan bisnis.

Akhir kata semoga majalah ilmiah "SOLUSI" dapat memberi manfaat yang sebesar-besarnya.

Hormat Kami 


\section{DAFTAR ISI}

PENGARUH WORK FAMILY CONFLICT, STRES KERJA DAN KEPEMIMPINAN TERHADAP TURNOVER INTENTION KARYAWAN (STUDI PADA SELURUH KARYAWAN BAGIAN PLANNING PRODUCTION AND INVENTORY CONTROL PT. PARKLAND WORLD INDONESIA JEPARA)

(Ferani; Kesi Widjajanti - Universitas Semarang)

STUDI SOFT SKILL LULUSAN PENDIDIKAN KEJURUAN DI TEMPAT KERJA

(Albert - Universitas Semarang)...

ANALISIS LINGKUNGAN INTERNAL DAN EKSTERNAL PADA UKM PREMIUM PLUS

LAUNDRY CABANG MULAWARMAN SEMARANG

(Nur Fitriani; Eviatiwi Kusumaningtyas Sugiyanto - Universitas Semarang)

FAKTOR-FAKTOR YANG MEMPENGARUHI PERTIMBANGAN TINGKAT

MATERIALITAS AUDIT

(Nita Andriyani; Dianing Ratna Wijayani; Sri Mulyani - Universitas Muria Kudus).

MANAJEMEN LABA DAN FAKTOR-FAKTOR YANG MEMPENGARUHINYA

(STUDI EMPIRIS PADA PERUSAHAN MANUFAKTUR DI BEI)

(Utami; Ardiani Ika Sulistyawati - Universitas Semarang)

PENDAPATAN ASLI DAERAH, DANA PERIMBANGAN, DAN SISA LEBIH PEMBIAYAAN ANGGARAN TERHADAP PENGALOKASIAN BELANJA MODAL: STUDI PADA

KABUPATEN/KOTA DI PROVINSI JAWA TENGAH

(Saifudin; Eka Ayu Siswanti - Universitas Semarang).

PERSEPSI PENGGUNA JASA TRANS JATENG TERHADAP KUALITAS PELAYANAN ANGKUTAN AGLOMERASI PERKOTAAN TRANS JATENG

(Studi Kasus Trans Jateng Koridor I Semarang (Tawang) - Bawen)

(Rr. Citra Aristi Amelia; Edy Mulyantomo; Sugeng Rianto - Universitas Semarang)

WORTHLESSNESS IS A POWER: MENGAPA ORANG BERSEDIA MENARUH UANG DI APLIKASI GO-PAY

(Rahoyo; Rr. Lulus Prapti N.S.S.; Asih Niati - Universitas Semarang).

ANALISIS PENGARUH KUALITAS PRODUK, PERSEPSI HARGA, DAN PROMOSI TERHADAP KEPUTUSAN PEMBELIAN WELLBLUE ALKALINE WATER PITCHER

STRATEGI PEMASARAN UNTUK MENINGKATKAN VOLUME PENJUALAN (STUDI KASUS PADA SHOFA CATERING)

(Wiki Sulistyaningsih; Teguh Ariefiantoro; Edy Suryawardana - Universitas Semarang)

PENGARUH CITRA MEREK, PERSEPSI HARGA, DAN KUALITAS PRODUK TERHADAP KEPUTUSAN PEMBELIAN SEPATU OLAH RAGA MEREK ADIDAS

(Studi di Kota Semarang)

(Rokh Eddy Prabowo; Kis Indriyaningrum; Anggita Dian Setyani - Universitas Stikubank Semarang) .121

PENGARUH KEMUDAHAN TERHADAP KEPUTUSAN MENGGUNAKAN E-BANKING PADA BNI 46 KC KARANGAYU SEMARANG DENGAN MINAT NASABAH DAN KEPERCAYAAN SEBAGAI VARIABEL MEDIASI

(Ahmad Sahri Romadon; Risma Nurhapsari - Universitas Semarang) 
PENELITIAN KEBERLANGSUNGAN USAHA ARDANI INDONESIA SEBAGAI UMKM BERBASIS INDUSTRI KREATIF

(Soegihartono - Universitas Semarang)

STRATEGI PELAYANAN BUS RAPID TRANSIT (BRT) TRANS SEMARANG

(Susanto - Universitas Semarang).....

ANALISIS PENGARUH KEPEMIMPINAN, STRES KERJA, DAN LINGKUNGAN KERJA TERHADAP KINERJA KARYAWAN BAGIAN PRODUKSI SEWING PT. SAMWON BUSANA INDONESIA SEMARANG

(Andana Budi Tami; Sri Yuni Widowati - Universitas Semarang). 


\title{
STUDI SOFT SKILL LULUSAN PENDIDIKAN KEJURUAN DI TEMPAT KERJA
}

\author{
Albert \\ albert@usm.ac.id \\ Fakultas Ekonomi Universitas Semarang
}

Diterima: Agustus 2020, Disetujui: September 2020, Dipublikasikan: Oktober 2020

\begin{abstract}
Vocational education graduates are equipped with many of the technical skills necessary to enter the work environment. Soft skills are also considered important but are often ignored by educational institutions.

This study aims to explore the importance of soft skills such as critical thinking, problem solving, acquiring new knowledge and information management, for vocational education graduates in their workplace and whether gender, industry type and current position play a role in differentiating soft skills. This study uses a quantitative research approach through distributing questionnaires to graduates of vocational education in Central Java. The responses were then analyzed statistically using SPSS.

The results showed that there was only a small correlation found between gender and vocational education graduates' critical thinking skills. Meanwhile, gender did not show any correlation with problem solving, acquiring new knowledge and information management. In addition, no correlation was found between industry type and current position with the four types of soft skills tested in this study. This concludes that only gender and critical thinking skills show a correlation with each other, whereas other demographic backgrounds namely type of industry and current positions held by graduates do not affect their soft skills in the workplace.
\end{abstract}

Keywords: graduates, vocational education, soft skills, workplace

\begin{abstract}
ABSTRAK
Lulusan pendidikan kejuruan dilengkapi dengan banyak keterampilan teknis yang diperlukan untuk memasuki lingkungan kerja. soft skill juga dianggap penting tetapi seringkali diabaikan pentingnya oleh institusi pendidikan.

Penelitian ini bertujuan untuk mengeksplorasi pentingnya soft skill seperti berpikir kritis, pemecahan masalah, memperoleh pengetahuan baru dan manajemen informasi, untuk lulusan pendidikan kejuruan di tempat kerja mereka dan apakah gender, tipe industri dan posisi saat ini memainkan peran dalam mendiferensiasi kemampuan soft skill. Penelitian ini menggunakan pendekatan penelitian kuantitatif melalui pendistribusian kuesioner kepada lulusan pendidikan kejuruan di Jawa Tengah. Respons kemudian dianalisis secara statistik menggunakan SPSS.

Hasil penelitian menunjukkan bahwa hanya ada sedikit korelasi yang ditemukan antara gender dan keterampilan berpikir kritis lulusan pendidikan kejuruan. Sementara
\end{abstract}


jenis kelamin tidak menunjukkan adanya korelasi dengan pemecahan masalah, memperoleh pengetahuan baru dan manajemen informasi. Selain itu, juga tidak ada korelasi yang ditemukan antara jenis industri dan posisi saat ini dengan keempat jenis soft skill yang diuji dalam penelitian ini. Hal ini menyimpulkan bahwa hanya gender dan kemampuan berpikir kritis yang menunjukkan korelasi satu sama lain, sedangkan latar belakang demografis lainnya yaitu jenis industri dan posisi saat ini yang dipegang oleh lulusan tidak mempengaruhi kemampuan soft skill mereka di tempat kerja.

Kata kunci: lulusan, pendidikan kejuruan, soft skill, tempat kerja

\section{PENDAHULUAN}

Lulusan dari pendidikan kejuruan dikenal memiliki keterampilan teknis untuk mempersiapkan mereka ke lingkungan tempat kerja. Namun seringkali lembaga pendidikan tinggi kejuruan justru mengabaikan kebutuhan soft skill yang diperlukan oleh mahasiswa. Hal ini didukung penelitian sebelumnya yang menemukan bahwa lulusan pendidikan kejuruan tidak efektif di tempat kerja karena tidak memiliki soft skill yang diperlukan oleh tempat kerja (Adnan et al, 2014). Davidson (2016) juga menyatakan bahwa produktivitas perusahaan dipengaruhi oleh kurangnya soft skill pada karyawan. Stewart et al (2016) juga memberikan pendapat serupa bahwa studi terbaru menunjukkan kesenjangan yang melebar antara harapan perusahaan dengan kemampuan lulusan perguruan tinggi.

Para peneliti telah berpendapat bahwa lulusan memerlukan berbagai jenis soft skill untuk mencapai kesuksesan di tempat kerja. Hasanefendic et al (2016) menyatakan bahwa soft skill penting adalah regulasi diri dan kepemimpinan. Pernyataan lain dari Deng et al (2014) yang mengatakan berdasarkan hasil penelitian bahwa soft skill yang penting adalah kreativitas dan kemampuan berpikir "di luar kotak". Di sisi lain, Gracia (2014) percaya bahwa lulusan harus dilengkapi dengan soft skill berikut: kemampuan untuk berpikir kritis, memecahkan masalah, keterampilan sosial, ketekunan, kreatif dan memiliki kontrol diri yang baik. Di sisi lain, Gilbert (2017) menyarankan keterampilan berikut sebagai soft skill yang paling dibutuhkan: membangun hubungan kerja eksternal, kesadaran budaya dan keragaman, kecerdasan emosional, memiliki kepercayaan moral yang menginspirasi, memiliki kemampuan untuk menginspirasi yaitu dapat dipercaya dan dapat berpikir dengan strategis. Sedangkan Davidson (2016) percaya bahwa soft skill yang sangat diperlukan adalah komunikasi, organisasi, kapasitas untuk kerja tim, ketepatan waktu, pemikiran kritis, kecerdasan sosial, kreativitas, dan kemampuan beradaptasi.

Antara berbagai jenis soft skill yang diteliti oleh para peneliti sebelumnya, penelitian ini lebih berfokus pada empat soft skill tertentu yaitu pemikiran kritis, pemecahan masalah, memperoleh pengetahuan baru (mekanisme keinginan belajar seumur hidup) dan kemampuan manajemen informasi. Hal ini didasarkan pada 
penelitian sebelumnya yang dilakukan oleh Adnan et al (2014), yang telah melakukan penelitian awal yang akhirnya mengelompokkan kuesioner menjadi empat soft skill utama seperti yang disebutkan sebelumnya.

\section{KAJIANPUSTAKA}

\section{Kemampuan Berpikir Kritis}

Kemampuan untuk berpikir kritis terhadap suatu masalah atau situasi tertentu dianggap sebagai salah satu soft skill yang paling penting untuk dimiliki oleh lulusan. Hal ini juga ditunjukkan sebagai salah satu hasil penelitian sebelumnya (Deng et al, 2014), di mana pemikiran kritis dipilih oleh pimpinan sebagai salah satu keterampilan paling penting yang di cari oleh perusahaan.

\section{Pemecahan masalah}

Pemecahan masalah dianggap sebagai salah satu keterampilan yang paling penting pada saat mewawancarai pencari kerja saat melamar pekerjaan (Radermacher et al, 2014). Kemampuan untuk memecahkan masalah yang timbul di tempat kerja dikenal penting karena akan secara signifikan mempengaruhi produktivitas perusahaan.

\section{Memperoleh Pengetahuan baru}

Proses pembelajaran tidak hanya melibatkan belajar tetapi juga untuk mengajarkan dan mengkomunikasikan informasi dan untuk memverifikasi bahwa pendapat yang diberikan selama ini benar dan akurat sehingga dapat dipegang teguh sebagai pengetahuan terutama dalam pekerjaan (Khamzah et al, 2017).

\section{Manajemen Informasi}

Manajemen informasi termasuk konsep tentang bagaimana cara menyaring informasi tertentu dan benar sehingga dapat menjadi pengetahuan yang akurat dan berguna. Manajemen informasi telah menjadi suatu hal yang sangat dibutuhkan dalam bidang bisnis dan komunikasi dan juga bidang pendidikan. Hal ini karena soft skill ini menjadi dasar untuk memahami pentingnya manajemen informasi pada saat lulusan bekerja di bidang-bidang yang lebih menantang. (Khamzah et al 2017).

\section{METODOLOGI}

Penelitian ini menggunakan pendekatan analisis kuantitatif. Kuesioner yang disiapkan dibangun berdasarkan penelitian sebelumnya dari Adnan et al (2014) tentang soft skill lulusan pendidikan kejuruan. Kuesioner kemudian didistribusikan kepada lulusan lembaga pendidikan kejuruan terkenal di Jawa Tengah yang sudah bekerja di berbagai lokasi dan jenis industri. Hasil yang diperoleh kemudian dianalisis menggunakan Paket Statistik untuk Ilmu Sosial (SPSS). 


\section{HASIL DAN DISKUSI}

Hasil dari penelitian ini menunjukkan adanya korelasi antara soft skill dengan gender berdasarkan analisis statistik seperti yang tersedia pada Tabel 1. Analisa statistik menunjukkan bahwa hanya pemikiran kritis yang ditemukan berkorelasi dengan jenis kelamin. Di sisi lain, pemecahan masalah, pengetahuan baru dan manajemen informasi tidak menunjukkan korelasi dengan jenis kelamin. Hal ini menunjukkan bahwa pria dan wanita tidak menunjukkan perbedaan dalam cara mereka memecahkan masalah, cara mereka dalam memperoleh pengetahuan baru dan keterampilan manajemen informasi mereka.

Table 1. Spearman's correlation antara jenis kelamin dan soft skill

\begin{tabular}{|c|c|c|c|}
\hline \multirow[t]{5}{*}{ Spearman's rho } & \multirow[t]{5}{*}{ Sig. } & & Gender \\
\hline & & Berpikir kritis & 0.005 \\
\hline & & Pemecahan masalah & 0.371 \\
\hline & & Pengetahuan baru & 0.166 \\
\hline & & Manajemen informasi & 0.845 \\
\hline
\end{tabular}

Sedangkan persentase antara jumlah pria dan wanita yang berpartisipasi pada penelitian ini dapat dilihat pada Gambar 1 dibawah.

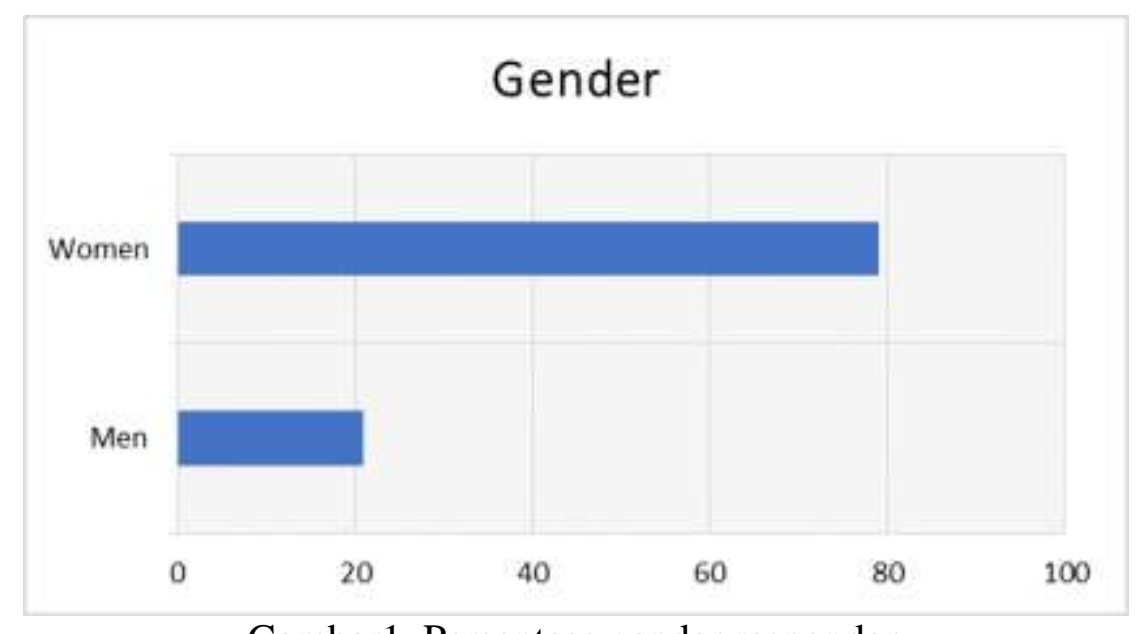

Gambar1. Persentase gender responden

Gambar 1 menunjukkan bahwa hampir $80 \%$ responden adalah perempuan dan hanya sekitar 20\% adalah laki-laki. Ini mungkin menunjukkan bahwa perempuan lebih bersedia untuk berpartisipasi dalam survei tersebut lebih dari laki-laki.

\section{Korelasi dengan Jenis Industri}

Berdasarkan analisis korelasi antara jenis industri dan soft skill pada responden di Tabel 2 menunjukkan bahwa tidak ada korelasi yang signifikan. 
Table 2. Spearman's correlation antara jenis industri dan soft skill

\begin{tabular}{|c|c|c|c|}
\hline \multirow{5}{*}{$\begin{array}{c}\text { Spearman's } \\
\text { rho }\end{array}$} & \multirow[t]{5}{*}{ Sig. } & \multicolumn{2}{|c|}{ Jenis industri } \\
\hline & & Berpikir kritis & 0.202 \\
\hline & & Pemecahan masalah & 0.883 \\
\hline & & Pengetahuan baru & 0.478 \\
\hline & & Manajemen informasi & 0.656 \\
\hline
\end{tabular}

Analisis di atas menunjukkan bahwa meskipun responden berasal dari berbagai jenis latar belakang industri, itu tidak mempengaruhi kemampuan mereka dalam berpikir kritis, pemecahan masalah, memperoleh pengetahuan baru dan manajemen informasi. Gambar 2 dibawah ini menunjukkan persentase latar belakang jenis industri responden. Dari dua belas latar belakang industri yang tersedia untuk dipilih, responden hanya memilih sembilan, sementara tidak ada responden dari industri pariwisata, pertambangan atau agribisnis yang ditemukan dalam survei ini.

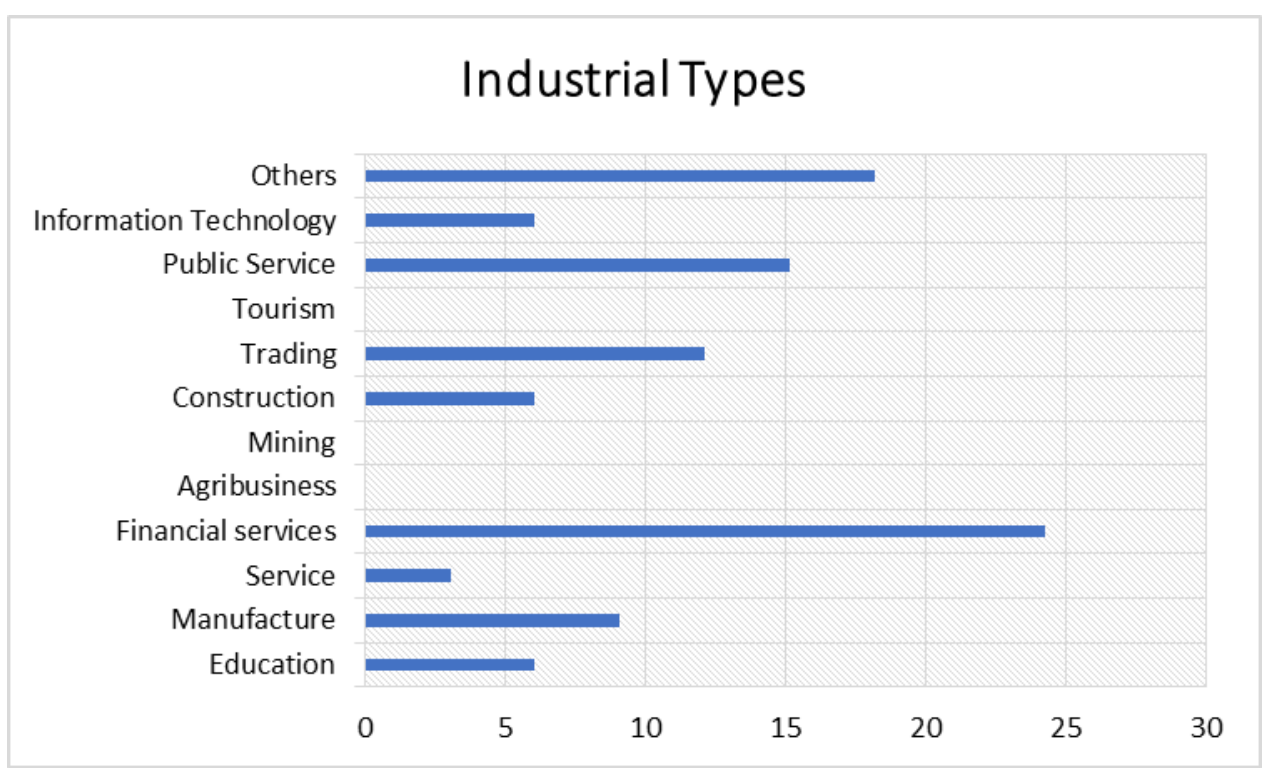

Gambar 2. Persentase latar belakang jenis industri dari responden

Grafik menunjukkan bahwa sebagian besar responden (hampir 25\%) berasal dari latar belakang layanan keuangan, diikuti oleh orang lain (hampir 20\%), layanan publik $(15 \%)$ dan perdagangan (lebih dari 10\%).

\section{Korelasi dengan Posisi Saat Ini}

Hasil analisis statistik untuk korelasi antara 4 jenis soft skill dengan posisi saat ini disediakan dalam Tabel 3. Pada tabel tersebut dapat dilihat bahwa bahwa keempat soft skill tidak menunjukkan korelasi dengan posisi saat ini.

Table 3. Spearman's correlation antara posisi saat ini dan soft skill

\begin{tabular}{lccc}
\hline Spearman's rho Sig. & & Posisi saat ini \\
\cline { 2 - 3 } & & Berpikir kritis & 0.417 \\
\cline { 2 - 3 } & & Pemecahan masalah & 0.977 \\
\cline { 2 - 3 } & & 0.682 \\
\cline { 2 - 3 } & $\begin{array}{c}\text { Pengetahuan baru } \\
\text { Manajemen } \\
\text { informasi }\end{array}$ & 0.311 \\
\hline
\end{tabular}


Hal ini menunjukkan bahwa apa pun posisi saat ini responden miliki, apakah itu karyawan tanpa posisi manajerial, karyawan dengan posisi manajemen yang lebih rendah / tengah / atas, atau sebagai pemilik bisnis, tidak mempengaruhi pemikiran kritis mereka, pemecahan masalah, memperoleh pengetahuan baru atau keterampilan manajemen informasi.

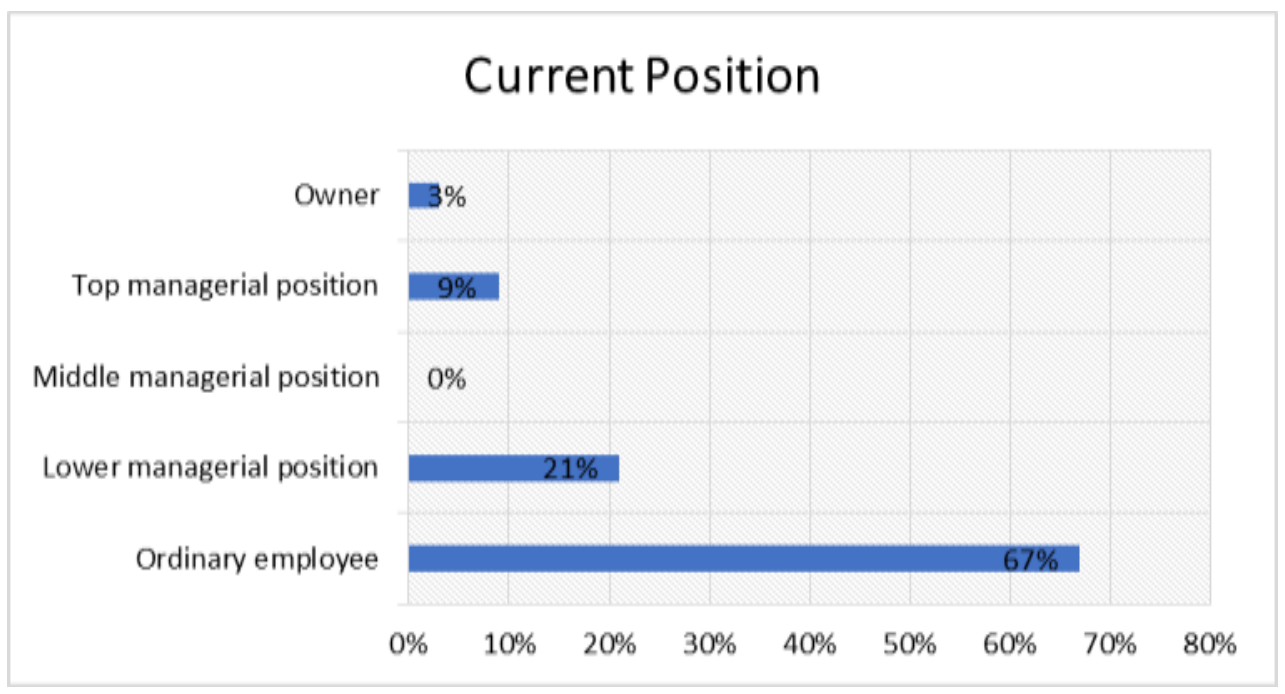

Gambar 3. Persentase posisi dari responden

Gambar 3 menunjukkan bahwa sebagian besar responden (67\%) adalah karyawan biasa tanpa posisi manajerial. Sekitar $21 \%$ responden memiliki posisi manajerial yang lebih rendah dan $9 \%$ memiliki posisi manajerial teratas. Ada juga $3 \%$ responden yang merupakan pemilik bisnis mereka sendiri.

\section{KESIMPULAN}

Berdasarkan hasil penelitian dapat disimpulkan bahwa hanya jenis kelamin yang mempengaruhi kemampuan berpikir kritis lulusan pendidikan kejuruan di tempat kerja, tetapi tidak mempengaruhi kemampuan dalam pemecahan masalah, memperoleh pengetahuan baru dan manajemen informasi. Kondisi demografis lainnya seperti posisi saat ini dan jenis industri terlihat juga tidak berpengaruh terhadap keempat jenis soft skill yang disurvei.

\section{REFERENCES}

Adnan, A. H. M., Ramalingam, S., Ilias, N., \& Tahir, T. M. (2014). Acquiring and Practicing soft skills: A Survey of Technical-Technological Undergraduates at a Malaysian Tertiary Institution. Procedia-Social and Behavioral Sciences, $123,82-89$.

Davidson, K. (2016). Employers find 'soft skills' like critical thinking in short supply. The Wall Street Journal, 30. 
Deng, L., Thomas, A., \& Trembach, S. (2014). Shaping the 21st-century information professional: A convergence of technical and "soft" skills for workplace success. Proceedings of the American Society for Information Science and Technology, 51(1), 1-4.

Garcia, E. (2016). The Need to Address Non-Cognitive Skills in the Education Policy Agenda1. In Non-cognitive skills and factors in educational attainment (pp. 3164). SensePublishers, Rotterdam.

Gibert, A., Tozer, W. C., \& Westoby, M. (2017). Teamwork, soft skills, and research training. Trends in ecology \& evolution, 32(2), 81-84.

Hasanefendic, S., Heitor, M., \& Horta, H. (2016). Training graduates for new jobs: The role of technical and vocational higher education and implications for science policy in Portugal. Technological Forecasting and Social Change, 113, 328340 .

Khamzah, N. A., Sah, S. M., \& Hussin, N. (2017). Information Management in Education. International Journal of Academic Research in Business and Social Sciences, 7(8), 743-749.

Radermacher, A., Walia, G., \& Knudson, D. (2014, May). Investigating the skill gap between graduating graduates and industry expectations. In Companion Proceedings of the 36th international conference on software engineering ( $\mathrm{pp}$. 291-300). ACM.

Stewart, C., Wall, A., \& Marciniec, S. (2016, July). Mixed signals: Do college graduates have the soft skills that employers want?. In Competition Forum (Vol. 14, No. 2, p. 276). American Society for Competitiveness. 